\title{
Sodium reduction and flavor enhancer addition in probiotic prato cheese: Contributions of quantitative descriptive analysis and temporal dominance of sensations for sensory profiling
}

\author{
H. L. A. Silva, ${ }^{,}$C. F. Balthazar, ${ }^{*}$ R. Silva, ${ }^{*} \dagger$ A. H. Vieira, ${ }^{*}$ R. G. B. Costa,‡ E. A. Esmerino, ${ }^{*}$ M. Q. Freitas, ${ }^{*}$ \\ and A. G. Cruz† ${ }^{1}$ \\ *Universidade Federal Fluminense, Faculdade de Veterinária, 24230-340 Niterói, Brazil \\ †Instituto Federal de Educação, Ciência e Tecnologia do Rio de Janeiro (IFRJ), Departamento de Alimentos, $20270-021$ Rio de Janeiro, Brazil \\ ‡Empresa de Pesquisa Agropecuária de Minas Gerais (EPAMIG), Instituto de Laticínios Cândido Tostes (ILCT), 36045-560 Juiz de Fora, \\ Minas Gerais, Brazil
}

\section{ABSTRACT}

Prato cheese, a typical ripened Brazilian cheese, contains high levels of sodium, and the excess intake of this micronutrient is associated with hypertension and cardiovascular diseases. A technological alternative to reduce the sodium content in foods is to replace $\mathrm{NaCl}$ with $\mathrm{KCl}$ and the addition of flavor enhancers. The present study aimed to combine quantitative descriptive analysis (QDA) and temporal dominance of sensations (TDS) to assess the sensory profile of reduced-sodium probiotic prato cheese with the addition of flavor enhancers. Five formulations of probiotic prato cheese were manufactured using $1 \%$ (wt/wt) salt as follows: $\mathrm{C} 1(100 \% \mathrm{NaCl}), \mathrm{C} 2(50: 50 \mathrm{NaCl}: \mathrm{KCl}), \mathrm{C} 3$ (50:50 NaCl: $\mathrm{KCl}+1 \%$ arginine), $\mathrm{C} 4(50: 50 \mathrm{NaCl}: \mathrm{KCl}$ $+1 \%$ yeast extract), and $\mathrm{C} 5(50: 50 \mathrm{NaCl}: \mathrm{KCl}+1 \%$ oregano extract). Both methods indicated that the addition of flavor enhancers modified the sensory profile of the reduced-sodium probiotic prato cheese. The QDA revealed that flavor enhancers - in particular, yeast and oregano extract - increased the saltiness of samples $\mathrm{C} 4$ and C5, respectively, and that the other flavor enhancer, arginine (sample C3), most modified the attributes of prato cheese. The TDS dominance curves revealed that the addition of yeast extract (sample C4) had a positive effect on cheese flavor because it minimized the bitter taste perception resulting from the addition of potassium chloride. Overall, QDA and TDS used together provided interesting insights for establishing the sensory profile of reduced-sodium probiotic prato cheese.

Key words: prato cheese, probiotic, flavor enhancer, quantitative descriptive analysis, temporal dominance of sensations

Received March 25, 2018.

Accepted June 7, 2018.

${ }^{1}$ Corresponding author: food@globo.com

\section{INTRODUCTION}

The reformulation of food represents an alternative approach to creating healthier products (Ferrão et al., 2016). In this sense, the supplementation of cheese with probiotic bacteria represents the aggregation of value to a product that already has benefits inherent in its composition, such as essential nutrients (Santiago-López et al., 2018). Cheese has a good potential for delivery of probiotic microorganisms into the human intestine, and the production of probiotic cheeses with acceptable or satisfactory sensory characteristics is achievable (Karimi et al., 2012b). In addition, probiotics added to cheese yield a wide spectrum of enzymes able to affect the biochemical events that influence the development of texture, flavor, and compounds with health benefits (Albenzio et al., 2013).

There is a need to reduce sodium in food because a positive correlation has been found between high sodium $(\mathrm{Na})$ intake and hypertension, osteoporosis, kidney stones, and cardiovascular diseases (Ayyash and Shah, 2011a). The reduction of sodium in cheeses represents a great challenge for the industry because salt has specific functions and influences taste, body, texture, and shelf life extension, being currently substituted by other salts, as KCl (Cruz et al., 2011). Indeed, the $\mathrm{NaCl}-\mathrm{KCl}$ blend has been used successfully in various cheeses with no adverse effects on cheese quality (Karimi et al., 2012a). Another interesting alternative to reduce sodium in foods is the use of flavor enhancers (Cruz et al., 2011), which are compounds that activate specialized receptor cells within the oral cavity, helping to reduce sodium without sacrificing flavor (Brandsma, 2006).

Prato cheese is a typical ripened Brazilian cheese that is similar to Danish cheeses such as Gouda and Danbo. It has great representation in the Brazilian market and composes about $20 \%$ of all cheeses produced in the country (Silva et al., 2017). Studies on 
the physicochemical and microbiological aspects of reduced-sodium probiotic prato cheese with the addition of flavor enhancers have been carried out (Silva et al., 2017, 2018a,b). However, there is no study on the sensory profile of this product and the quality attributes that lead to a better acceptance.

Quantitative descriptive analysis (QDA) is a method for qualifying the type and quantifying the intensity of the sensory properties immediately after sensory stimulation (Stone and Sidel, 2004) and has been recognized as a tool for measurement and optimization of the sensory attributes of different dairy products (Janiaski et al., 2016; Ferrão et al., 2018). Temporal dominance of sensations (TDS) has been widely used as a temporal descriptive technique to provide information on the sequence and duration of dominant sensations (Galmarini et al., 2017). It focuses on the dominant attributes rather than quantifying attribute intensity, explaining the consumers' perception and accurately identifying the sensations that determine the hedonic perception.

Quantitative descriptive analysis and TDS can provide complementary information about the sensory interactions in foods (Labbe et al., 2009; Bruzzone et al., 2013; Devezeaux de Lavergne et al., 2015; Braghieri et al., 2016). The combination of QDA and TDS in a sequential approach can be used in a commercial context and enables a fuller profile of the product category $(\mathrm{Ng}$ et al., 2012). The present study aimed to evaluate the effect of sodium reduction and the addition of flavor enhancers on the dynamic and static sensory profile of probiotic prato cheese using both the TDS and QDA methods.

\section{MATERIALS AND METHODS}

\section{Cheese Processing}

Prato cheese was produced by a traditional manufacturing method as described by Silva et al. (2017). The experiment was conducted using $120 \mathrm{~L}$ of whole pasteurized milk $\left(65^{\circ} \mathrm{C} / 30 \mathrm{~min}\right)$. Milk was cooled to 32 to $34^{\circ} \mathrm{C}$, and the frozen lactic and probiotic bacteria cultures were added directly to the milk and incubated for $40 \mathrm{~min}$. Then, calcium chloride $(80 \mathrm{~mL} / 120 \mathrm{~L}$ of milk), annatto dye $(36 \mathrm{~mL} / 120 \mathrm{~L}$ of milk), and coagulant (Ha La 1175, Chr. Hansen, Valinhos, SP, Brazil) sufficient to coagulate the milk within 35 to $50 \mathrm{~min}$ were added. The curd was cut into $1-\mathrm{cm}$ cubes and submitted to slow, continuous mixing for $15 \mathrm{~min}$, which was followed by removal of part of the whey (30\%) and further heating to $42^{\circ} \mathrm{C}$ by progressively adding hot water $\left(25 \mathrm{~L}\right.$ at $\left.80^{\circ} \mathrm{C}\right)$ to increase the temperature by $1^{\circ} \mathrm{C}$ every $3 \mathrm{~min}$. This temperature was maintained for $40 \mathrm{~min}$, and then the whey was drained off. Five portions were separated [probiotic control with $100 \%$ of $\mathrm{NaCl}$ and 4 formulations with partial substitution of $\mathrm{NaCl}$ by $\mathrm{KCl}(50 \%)]$, and the ingredients corresponding to each formulation were added in a dry way by manual homogenization: $1 \mathrm{NaCl}: 1 \mathrm{KCl}$ (wt/wt); $1 \mathrm{NaCl}: 1 \mathrm{KCl}$ (wt/wt) and 1\% (wt/wt) arginine (Vetec, Rio de Janeiro, Brazil); $1 \mathrm{NaCl}: 1 \mathrm{KCl}$ (wt/wt) and 1\% (wt/wt) yeast extract from Saccharomyces cerevisiae (Bionis YE GMX 18, Biorigin, Lençóis Paulistas, SP, Brazil); and $1 \mathrm{NaCl}: 1 \mathrm{KCl}$ (wt/wt) and 1\% (wt/wt) of oregano extract. Therefore, the experimental design comprised 5 different cheese formulations made with $1 \%$ salt as follows: $\mathrm{NaCl}+$ Lactobacillus casei $(\mathbf{C 1}), 1: 1 \mathrm{NaCl}: \mathrm{KCl}$ $(\mathrm{wt} / \mathrm{wt})+$ L. casei $(\mathbf{C 2}), 1: 1 \mathrm{NaCl}: \mathrm{KCl}(\mathrm{wt} / \mathrm{wt})+1 \%$ arginine (wt/wt) + L. casei (C3), 1:1 NaCl:KCl (wt/ $\mathrm{wt})+1 \%$ yeast extract $(\mathrm{wt} / \mathrm{wt})+L$. casei $(\mathbf{C} 4)$, and $1: 1 \mathrm{NaCl}: \mathrm{KCl}(\mathrm{wt} / \mathrm{wt})+1 \%$ oregano extract (wt/wt) + L. casei (C5).

\section{Descriptive Analysis}

The samples were analyzed using QDA as described by Stone et al. (2012). The assessors were recruited among students and employees of the Federal Fluminense University Faculty of Veterinary Medicine (6 women and 4 men, aged 25-40 yr).

In the terminology development phase, the assessors elicited 20 descriptors after consensus. The main descriptors used for evaluating appearance were brightness and color. For the attribute aroma, the descriptors were sour, sweet, buttery, fine herbs, and typical, and the descriptors buttery, fine herbs, and typical were used to characterize the flavor of the samples. For taste, the descriptors were salty, sweet, sour, and bitter, and aftertaste was described using bitter aftertaste and buttery aftertaste. The descriptors used to evaluate texture were hardness, cohesiveness, fracturability, and adhesiveness.

After the terminology development phase, the panelists were trained over five 2 -h sessions for the evaluation of reduced-sodium probiotic prato cheese. The training sessions consisted of evaluating the experimental prato cheeses using the descriptive terms developed to describe and quantify the attributes appearance, texture, aroma, flavor, taste, and aftertaste.

The samples were evaluated in triplicate over four 2-h sessions according to a balanced design. All attributes were rated on a $150-\mathrm{mm}$ unstructured line scale anchored at the extremities with "not detected" and "high." Both the definitions of descriptive terms (Table 1) and the reference materials were routinely reviewed by the panelists before evaluation of the samples. This procedure was repeated until a panel consensus was achieved. Each sample was served monadically, and 
unsalted crackers and filtered tap water were provided as palate cleansers (Macfie et al., 1989). At each testing period, 2 intact pieces of the sample were presented with random 3 -digit codes in individual booths.

\section{TDS}

The same assessors $(\mathrm{n}=10)$ trained in QDA performed the TDS test, as recommended by Pineau et al. (2009). The panel had no previous experience using TDS; therefore, panelists received explanations of the concepts of the test and correct use of Sensomaker data collection software (Pinheiro et al., 2013) and attended six 1-h training sessions. The panelists were introduced to the notion of temporality of sensations using the analogy of an orchestra playing music. A dominant sensation was defined as a sensation that triggers the most attention at a given time.

The attributes were selected according to Braghieri et al. (2009), who reported that taste and flavor were the most influential attributes driving consumer liking. Six main descriptors were selected as follows: salty, sweet, sour, bitter, buttery, and fine herbs. The number of attributes per evaluation (maximum of 10 attributes) and the randomized presentation of program attributes on the display were conducted as proposed by Pineau et al. (2012).

The TDS analysis was performed according to Rodrigues et al. (2014). After instructions were given, the panelists were asked to click on the "start" button and during $5 \mathrm{~s}$ put the sample (approximately $5 \mathrm{~g}$ ) in their mouth and immediately start the evaluation. Using the mouse, the participants were requested to select the dominant taste over a duration of $35 \mathrm{~s}$. They were told that the dominant taste is the taste that is perceived with the greatest clarity and intensity. A button on the computer screen was presented for evaluation of each of the 6 descriptors. The conditions were determined by TDS pretests considering the time spent for each panelist to evaluate the cheese samples. The samples (approximately $5 \mathrm{~g}$ ) were balanced and coded with 3 -digit numbers drawn from a table of random numbers, presented in monadic order (Macfie et al., 1989), and evaluated over three 1-h sessions in triplicate according to a balanced design.

\section{Data Analysis}

Data obtained from QDA were submitted to 1-way ANOVA (product as fixed effect) and Tukey's test at the $5 \%$ level of significance (Stone et al., 2012). Additionally, QDA data were submitted to principal component analysis (PCA; Ferrão et al., 2018). We used XLSTAT software version 2018.1 (Addinsoft, Paris, France) to provide a further multivariate graphical representation of the product space.

The TDS curves of the samples were plotted according to the methodology proposed by Pineau et al. (2009) directly through the Sensomaker software (Pinheiro et al., 2013). Two lines were drawn on the TDS graphs for each sample: a line referring to chance level, and a significance level. The chance level marks the dominance rate at which an attribute can be chosen at random, whereas the significance level is the minimum value of this ratio to be considered significantly dominant (Pineau et al., 2009). For this calculation, the confidence interval for the binominal ratio was used and based on assumptions of independence and normal approximation (Rodrigues et al., 2014).

\section{RESULTS AND DISCUSSION}

\section{QDA}

Table 1 summarizes all 20 sensory attributes and their definitions and reference standards, and Table 2 shows the mean scores for the attributes appearance, aroma, flavor, taste, and texture of each sample. Significant differences $(P<0.05)$ were identified for all 20 attributes. Although most findings have shown that substitution of sodium chloride by $50: 50 \mathrm{NaCl}: \mathrm{KCl}$ blends does not result in biochemical, microbiological, or textural alterations, some studies have reported that $\mathrm{NaCl}: \mathrm{KCl}$ blends at this proportion do affect the sensory quality of cheeses (Cruz et al., 2011; Da Silva et al., 2014).

The first and second dimensions of the PCA of descriptive analysis data explained $87.7 \%$ of the total variance. As shown in Figure 1, the samples C1, C2, $\mathrm{C} 4$, and C5 were located to the right of the first dimension, and C1 (control), C2 (reduced sodium), an C4 (reduced sodium with addition of yeast extract) were characterized by the descriptors typical aroma, buttery aroma, typical flavor, buttery flavor, and salty taste. The sample C5 (reduced sodium with oregano extract) was characterized by fine herbs aroma, fine herbs flavor, sour taste, and bitter taste. On the contrary, the sample C3 was characterized by sour aroma and sweet taste. The samples $\mathrm{C} 1, \mathrm{C} 2$, and $\mathrm{C} 4$ were not significantly discriminated in the first 2 dimensions of the PCA because their confidence ellipses overlapped.

Regarding the sensory profile of the experimental cheeses, although the formulations $\mathrm{C} 1, \mathrm{C} 2, \mathrm{C} 3, \mathrm{C} 4$, and C5 were statistically different from each other $(P<$ 0.05 ) for the attribute appearance, the cheeses C1, C2, $\mathrm{C} 4$, and C5 showed lower brightness and a more yellowish color. The formulation C3 presented the highest score for the attribute brightness (10.05) and the lowest 
SILVA ET AL.

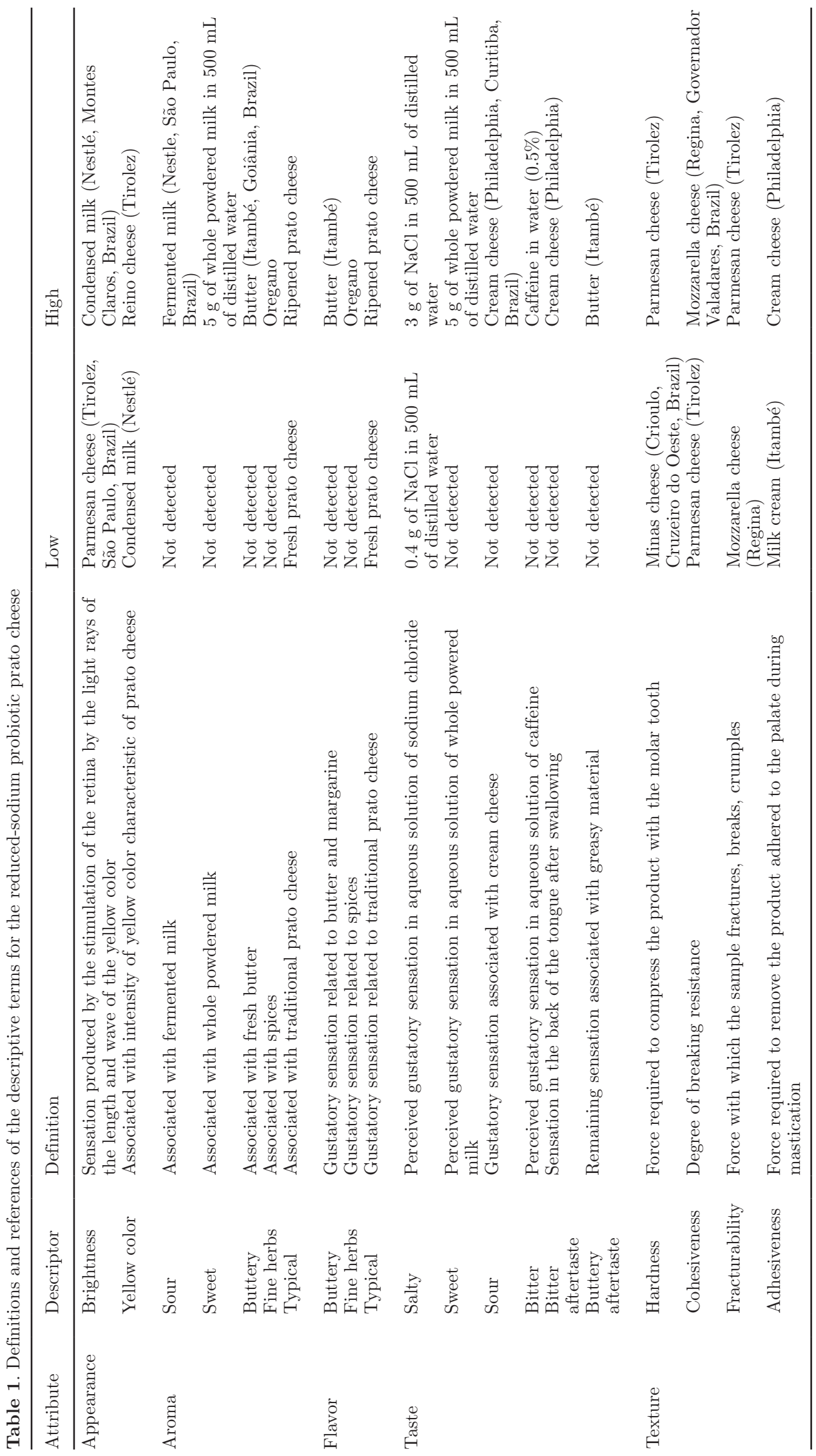


score for yellow color (2.51), which stood out as the clearest sample with significant differences from the others $(P<0.05)$. This lighter color may be due to the presence of arginine used as a flavor enhancer. Felicio et al. (2016) studied Minas Frescal cheese and found that arginine negatively affected the visual appearance of the cheeses due to the water retention capacity of this $\mathrm{AA}$ in the cheese matrix.

According to Cruz et al. (2011), salt is also described as a factor that influences the formation and development of aroma compounds. However, the samples C1 (control with $100 \% \mathrm{NaCl}$ ) and $\mathrm{C} 2$ (reduced sodium without the addition of flavor enhancers) were very similar for all aroma-related attributes $(P>0.05)$. The addition of flavor enhancers (C3, C4, and C5) affected the attribute aroma, with significant differences among the samples $(P<0.05)$. No significant $(P>0.05)$ differences were observed for the sweet aroma for all cheeses. The formulation C3 (reduced sodium with the addition of arginine) presented the lowest score for typical aroma (2.04) and buttery aroma (2.85); thus, it was considered the sourest sample (6.16), with significant differences from the others $(P<0.05)$. For the aroma of the fine herbs, the sample C5 (reduced sodium with the addition of oregano extract) received the highest score (13.59), with a significant difference $(P<0.05)$ among the samples. The higher intensity of fine herbs aroma in cheese C5 is due to oregano, which is an aromatic plant widely used in raw or cooked foods, yielding a distinct and pleasant aroma and taste (Camo et al., 2011).

Significant differences were also observed for the attribute flavor among the treatments $(P<0.05)$. The sample C3 (reduced sodium with the addition of arginine) presented the lowest score for the descriptor buttery flavor $(3.06 ; P<0.05)$, although similar scores were observed among the samples. The samples $\mathrm{C} 1$ and $\mathrm{C} 2$ (reduced sodium without the addition of flavor enhancers) had the highest scores (9.81 and 9.61, respectively) for the typical prato cheese flavor. In addition, significant differences were observed for the samples C3, C4, and C5 when compared with the control $(P<0.05)$, and $\mathrm{C} 3$ showed the lowest score $(2.13)$ for this descriptor. This result reveals that the addition of flavor enhancers can modify the descriptor typical flavor. The sample C5 (reduced sodium with the addition of oregano extract) presented the highest score for

Table 2. Sensory profiling of probiotic prato cheese using descriptive analysis

\begin{tabular}{|c|c|c|c|c|c|c|}
\hline \multirow[b]{2}{*}{ Attribute $^{1}$} & \multirow[b]{2}{*}{ Descriptor } & \multicolumn{5}{|c|}{ Cheese $^{2}$} \\
\hline & & $\mathrm{C} 1$ & $\mathrm{C} 2$ & C3 & $\mathrm{C} 4$ & C5 \\
\hline \multirow[t]{2}{*}{ Appearance } & Brightness & $3.69^{\mathrm{c}}$ & $4.96^{\mathrm{b}}$ & $10.05^{\mathrm{a}}$ & $4.57^{\mathrm{bc}}$ & $4.34^{\mathrm{bc}}$ \\
\hline & Color & $12.24^{\mathrm{a}}$ & & $2.51^{\mathrm{c}}$ & $8.76^{\mathrm{b}}$ & $10.47^{\mathrm{ab}}$ \\
\hline \multirow[t]{5}{*}{ Aroma } & Sour & $4.39^{\mathrm{b}}$ & $4.03^{\mathrm{b}}$ & $6.16^{\mathrm{a}}$ & $4.79^{\mathrm{b}}$ & $4.08^{\mathrm{b}}$ \\
\hline & Sweet & $2.47^{\mathrm{a}}$ & $2.51^{\mathrm{a}}$ & $2.47^{\mathrm{a}}$ & $2.32^{\mathrm{a}}$ & $1.90^{\mathrm{a}}$ \\
\hline & Buttery & $3.68^{\mathrm{b}}$ & $4.12^{\mathrm{ab}}$ & $2.85^{\mathrm{c}}$ & $4.73^{\mathrm{a}}$ & $4.23^{\mathrm{ab}}$ \\
\hline & Fine herbs & $0.52^{\mathrm{b}}$ & $0.51^{\mathrm{b}}$ & $0.51^{\mathrm{b}}$ & $0.39^{\mathrm{b}}$ & $13.59^{\mathrm{a}}$ \\
\hline & Typical & $8.39^{\mathrm{a}}$ & $8.20^{\mathrm{a}}$ & $2.04^{\mathrm{c}}$ & $7.64^{\mathrm{a}}$ & $5.66^{\mathrm{b}}$ \\
\hline \multirow[t]{3}{*}{ Flavor } & Buttery & $5.35^{\mathrm{ab}}$ & $4.91^{\mathrm{ab}}$ & $3.06^{\mathrm{c}}$ & $5.39^{\mathrm{a}}$ & $4.52^{\mathrm{b}}$ \\
\hline & Fine herbs & $0.43^{\mathrm{b}}$ & $0.55^{\mathrm{b}}$ & $0.34^{\mathrm{b}}$ & $0.40^{\mathrm{b}}$ & $13.75^{\mathrm{a}}$ \\
\hline & Typical & $9.81^{\mathrm{a}}$ & $9.61^{\mathrm{a}}$ & $2.13^{\mathrm{d}}$ & $8.01^{b}$ & $5.95^{\mathrm{c}}$ \\
\hline \multirow[t]{6}{*}{ Taste } & Salty & $8.41^{\mathrm{a}}$ & $6.27^{\mathrm{b}}$ & $5.07^{\mathrm{c}}$ & $9.11^{\mathrm{a}}$ & $8.87^{\mathrm{a}}$ \\
\hline & Sweet & $1.74^{\mathrm{b}}$ & $2.07^{\mathrm{a}}$ & $2.32^{\mathrm{a}}$ & $2.19^{\mathrm{a}}$ & $2.02^{\mathrm{a}}$ \\
\hline & Sour & $5.76^{\mathrm{b}}$ & $6.45^{\mathrm{ab}}$ & $5.33^{\mathrm{b}}$ & $6.32^{\mathrm{ab}}$ & $7.44^{\mathrm{a}}$ \\
\hline & Bitter & $5.78^{\mathrm{c}}$ & $7.85^{\mathrm{b}}$ & $6.49^{\mathrm{c}}$ & $6.21^{\mathrm{c}}$ & $8.86^{\mathrm{a}}$ \\
\hline & Bitter aftertaste & $6.41^{\mathrm{c}}$ & $7.80^{\mathrm{b}}$ & $7.19^{\mathrm{bc}}$ & $6.98^{\mathrm{bc}}$ & $9.79^{\mathrm{a}}$ \\
\hline & Buttery aftertaste & $3.46^{\mathrm{b}}$ & $3.26^{\mathrm{bc}}$ & $2.49^{\mathrm{c}}$ & $5.25^{\mathrm{a}}$ & $5.09^{\mathrm{a}}$ \\
\hline \multirow[t]{4}{*}{ Texture } & Hardness & $6.75^{\mathrm{a}}$ & $5.68^{\mathrm{b}}$ & $5.18^{\mathrm{bc}}$ & $6.60^{\mathrm{a}}$ & $4.61^{\mathrm{c}}$ \\
\hline & Cohesiveness & $7.23^{\mathrm{c}}$ & $9.11^{\mathrm{b}}$ & $3.72^{\mathrm{d}}$ & $7.34^{\mathrm{c}}$ & $10.93^{\mathrm{a}}$ \\
\hline & Fracturability & $5.01^{\mathrm{b}}$ & $4.09^{\mathrm{b}}$ & $8.49^{\mathrm{a}}$ & $5.11^{\mathrm{b}}$ & $2.94^{\mathrm{c}}$ \\
\hline & Adhesiveness & $6.59^{\mathrm{b}}$ & $6.81^{\mathrm{b}}$ & $3.16^{\mathrm{c}}$ & $7.11^{\mathrm{ab}}$ & $8.01^{\mathrm{a}}$ \\
\hline \multicolumn{7}{|c|}{$\begin{array}{l}\text { a-d Different superscripts within a row imply significant difference according to Tukey's test }(P<0.05) \text { amon } \\
\text { treatments (cheeses). }\end{array}$} \\
\hline \multicolumn{7}{|c|}{${ }^{1}$ Attributes were evaluated in a $15-\mathrm{cm}$ unstructured intensity scale. } \\
\hline \multicolumn{7}{|c|}{$\begin{array}{l}{ }^{2} \text { The experimental design comprised } 5 \text { different cheese formulations made with } 1 \% \text { salt as follows: } \mathrm{C} 1(\mathrm{NaCl} \\
+ \text { Lactobacillus casei }), \mathrm{C} 2(1: 1 \mathrm{NaCl}: \mathrm{KCl} \mathrm{wt} / \mathrm{wt}+\text { L. casei }), \mathrm{C} 3(1: 1 \mathrm{NaCl}: \mathrm{KCl} \mathrm{wt} / \mathrm{wt}+1 \% \text { arginine wt/wt } \\
+ \text { L. casei }), \mathrm{C} 4(1: 1 \mathrm{NaCl}: \mathrm{KCl} \mathrm{wt} / \mathrm{wt}+1 \% \text { yeast extract wt/wt }+ \text { L. casei }), \mathrm{C} 5(1: 1 \mathrm{NaCl}: \mathrm{KCl} \mathrm{wt} / \mathrm{wt}+1 \% \\
\text { oregano extract wt/wt }+ \text { L. casei }) \text {. }\end{array}$} \\
\hline
\end{tabular}




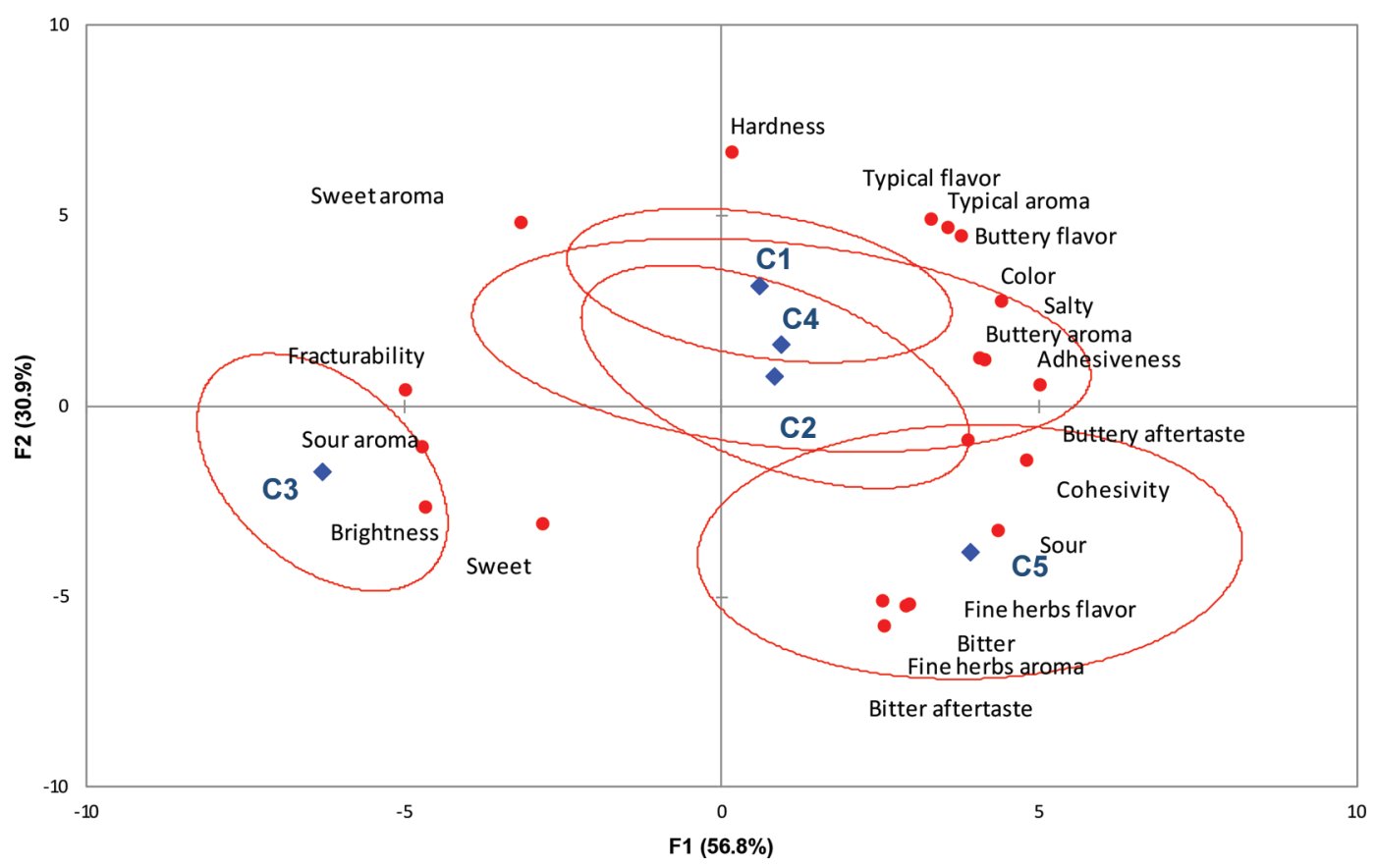

Figure 1. Principal component analysis (PCA) bidimensional map of sensory attributes of cheeses using descriptive analysis. The experimental design comprised 5 different cheese formulations made with $1 \%$ salt as follows: $\mathrm{C} 1$ ( $\mathrm{NaCl}+$ Lactobacillus casei), $\mathrm{C} 2$ (1:1 $\mathrm{NaCl}$ :KCl wt/ $\mathrm{wt}+$ L. casei $), \mathrm{C} 3(1: 1 \mathrm{NaCl}: \mathrm{KCl} \mathrm{wt} / \mathrm{wt}+1 \%$ arginine wt/wt + L. casei $), \mathrm{C} 4(1: 1 \mathrm{NaCl}: \mathrm{KCl} \mathrm{wt} / \mathrm{wt}+1 \%$ yeast extract wt/wt + L. casei $)$, and C5 (1:1 NaCl:KCl wt/wt $+1 \%$ oregano extract wt/wt + L. casei $). \mathrm{F} 1$ and $\mathrm{F} 2=$ first and second dimensions of PCA data, respectively. Color version available online.

the descriptor fine herbs flavor (13.75), as also reported for fine herbs aroma, with significant differences $(P<$ 0.05) from all formulations.

For the attribute taste, the formulations presented a very distinct profile. The sample $\mathrm{C} 1$ (control) presented the highest score $(8.41)$ with significant differences $(P$ $<0.05$ ) when compared with $\mathrm{C} 2$ (reduced sodium without the addition of flavor enhancer; 6.27$)$. This result is in accordance with Da Silva et al. (2014), who found that most of the sodium substitutes had salting potencies below that of sodium chloride. However, 2 samples containing flavor enhancers, C4 (reduced sodium with the addition of yeast extract) and C5 (reduced sodium with the addition of oregano extract), showed mean scores similar to $\mathrm{C} 1$ (9.11 and 8.87, respectively), without significant differences $(P>0.05)$. Thus, for the trained panelists, the flavor enhancers used in $\mathrm{C} 4$ and C5 led to an equivalent saltiness when compared with the control. Flavor enhancers are responsible for umami, brothy, and savory taste, which can be an opportunity to produce low-sodium products with high saltiness intensity (Desmond, 2006). Although the formulation C3 (reduced sodium with addition of arginine) contained the flavor enhancer, it exhibited the lowest score for salty taste (5.07), differing significantly $(P<0.05)$ from the other formulations. The significant difference may be due to the AA arginine, which retained water in cheese and possibly decreased the salt concentration. Regarding sweet taste, the samples presented low and similar scores. For the descriptors sour taste and bitter taste, the sample C5 (reduced sodium with the addition of oregano extract) presented the highest scores for both descriptors (7.44 and 8.86, respectively; $P<0.05)$ and the highest score (9.79) for bitter aftertaste. Ghawi et al. (2014) found a significant increase in bitterness with the addition of oregano in reduced-salt soup, which may be undesirable to some consumers. However, it was observed that the other samples containing flavor enhancers, C3 and C4, had lower scores for bitter taste when compared with the sample without addition of flavor enhancer $(\mathrm{C} 2 ; P<$ $0.05)$, which was similar to the control $(\mathrm{C} 1 ; P>0.05)$. This result suggests that the flavor enhancers, in the amount used in the present study, were able to mask the bitter taste produced by the partial replacement of $\mathrm{NaCl}$ with $\mathrm{KCl}$.

Regarding the attribute texture, the control sample (C1) showed the highest average for hardness (6.75). This finding is in agreement with the results of Ayyash et al. (2013), Ayyash and Shah (2011b), and Ayyash et al. (2011), who reported an increase in hardness of Mozzarella, Halloumi, and Nabulsi salted with only $\mathrm{NaCl}$ when compared with those made with partial replacement of $\mathrm{NaCl}$ with $\mathrm{KCl}$. Sample C5 had a lower 
hardness (4.61) and fracturability (2.94). It is assumed that a less-hard cheese fractures less easily because it is softer, which justifies the values found for these 2 descriptors. This sample also presented higher cohesiveness (10.93) and adhesiveness (8.01). In contrast, the sample C3 showed the highest fracturability score (8.49) and lower cohesiveness (3.72) and adhesiveness (3.16).

\section{TDS}

Unlike QDA, which is a technique of static perception, TDS provided dominance curves to illustrate the temporal changes of dominant attributes during and after the chewing process. According to Rodrigues et al. (2014), the TDS technique is also relevant for the development of reduced-sodium products. The use of other salts as $\mathrm{NaCl}$ substitutes can promote unpleasant tastes such as metallic, bitter, and astringent, and this temporal analysis allows for a descriptive evaluation of the products throughout chewing time. Figure 2 shows the smoothed TDS curves with the sensory profile of the samples (C1, C2, C3, C4, and C5) related to the attributes buttery, fine herbs, salty, sweet, sour, and bitter throughout the $35 \mathrm{~s}$ of evaluation. Both the chance level (0.13) and the significant level (0.25) were determined and plotted on the TDS curves for interpretation of the results.

The TDS curves show that the formulation C1 (control) presented 3 dominant flavors. The first perceived and mainly dominant sensation was salty, with a maximum salinity dominance rate of approximately 0.48 , perceived during $12 \mathrm{~s}$. However, the reduced-sodium probiotic prato cheeses containing $\mathrm{KCl}(\mathrm{C} 2, \mathrm{C} 3, \mathrm{C} 4$, and C5) did not result in the perception of salty taste and did not reach the significance level. These results are in accordance with Cruz et al. (2011), who stated that $\mathrm{NaCl}$ is the only salt that promotes the manifestation of a pure salty taste. However, Rodrigues et al. (2014) reported that it is possible to make Mozzarella cheese using an $\mathrm{NaCl}$ and $\mathrm{KCl}$ blend, which exhibited a salty taste similar to that made only with $\mathrm{NaCl}$. The sour and bitter tastes were observed in sample $\mathrm{C} 1$, with a low dominance rate and duration of $2 \mathrm{~s}$ and $4 \mathrm{~s}$. Prato cheese undergoes a more intense proteolysis and may present this defect (bitter taste) during ripening (Augusto et al., 2005).

As shown in the TDS dominance curves, the buttery, sour, and bitter sensations were dominant in $\mathrm{C} 2$ (reduced sodium without the addition of flavor enhancers). The buttery flavor occurred with a low dominance rate during $4 \mathrm{~s}$, whereas the sour and bitter tastes were perceived as dominant for a duration of 3 and $1 \mathrm{~s}$, respectively. Sodium reduction in foods not only reduces the perceived saltiness but also is associated with a wide range of complex taste interactions, which may negatively affect the liking of foods. In turn, potassium chloride elicits weak saltiness and metallic and bitter taste at higher concentrations, thus limiting its utility in food (Liem et al., 2011). Also, $\mathrm{KCl}$ tends to cause considerable sourness perception in addition to increasing proteolysis, water activity, acidity, and lower firmness (Cruz et al., 2011).

The TDS curves showed that the sample C3 (reduced sodium with the addition of arginine) presented 2 dominant sensations, sour and bitter tastes. The bitter taste occurred with a high dominance rate between 15 and $20 \mathrm{~s}$, whereas the sour taste was perceived as dominant for $10 \mathrm{~s}$. For the sample C4, buttery and sour were the 2 dominant sensations observed. The buttery taste occurred with a low dominance rate and was perceived during $5 \mathrm{~s}$. The sour taste was perceived as dominant by $36 \%$ of the panelists for a duration of $12 \mathrm{~s}$. The sour taste was identified as dominant in most of the formulations with partial substitution of $\mathrm{NaCl}$ by $\mathrm{KCl}$. According to Da Silva et al. (2014), the $\mathrm{NaCl}$ substitutes often generate undesirable tastes in strong intensity. The use of salt substitutes is mainly limited due to the association of nonsalty tastes, especially sour taste.

The TDS curves also show that sample C5 presented 2 dominant flavors, fine herbs and bitter taste, whereas the term fine herbs was perceived as mainly dominant in sample C 5 by $64 \%$ of panelists during $25 \mathrm{~s}$, probably due to the presence of oregano, a flavor enhancer used in this sample. The bitter taste was perceived with a low dominance for a duration of $6 \mathrm{~s}$. According to Ghawi et al. (2014), herbs and spices added must be carefully studied to avoid intense flavor that might detract from the main flavor of the product. In addition, the use of $\mathrm{KCl}$ as a substitute for $\mathrm{NaCl}$ results in the perception of bitter taste during chewing by TDS analysis, which was perceived as dominant in almost all samples, surpassing the significant level. However, sample C4 (reduced sodium with the addition of yeast extract) did not reach this level. This result suggests that the effect of the flavor enhancer yeast extract in reduced-sodium probiotic prato cheese minimized the perception of unpleasant taste (bitterness) and stood out as the most suitable flavor enhancer for masking the off-flavors. Yeast extracts are a natural source of several volatile compounds and have been widely used as flavoring agents and as precursors to the formation of pleasant compounds responsible for flavor and aroma (Mahadevan and Farmer, 2006). Flavor enhancers can confer the umami, brothy, and savory flavors in foods; thus, it can be used to improve the flavor of reducedsodium products (Brandsma, 2006). 


\section{Comparison of QDA and TDS Results}

The sample $\mathrm{C} 1$ was rated for a higher intensity of salt (8.41), bitter (5.78), and sour taste (5.76) in QDA, and the TDS curves showed that the salty flavor stood out as dominant. The sample $\mathrm{C} 2$ was rated for a higher intensity of the terms bitter (7.85), sour (6.45), and salty (6.27) in QDA and was characterized by buttery, sour, and bitter as the last dominant sensation in TDS. The sample C3 was rated for a higher intensity of bitter (6.49), sour (5.33), and salty (5.07) in QDA and was characterized by the dominance of bitter and sour taste in TDS. Sample C4 was rated for a higher intensity of salt (9.11), sour (6.32), and bitter (6.21) in QDA, and the TDS dominance curves identified the terms sour and bitter as dominant in this sample. Sample C5 was
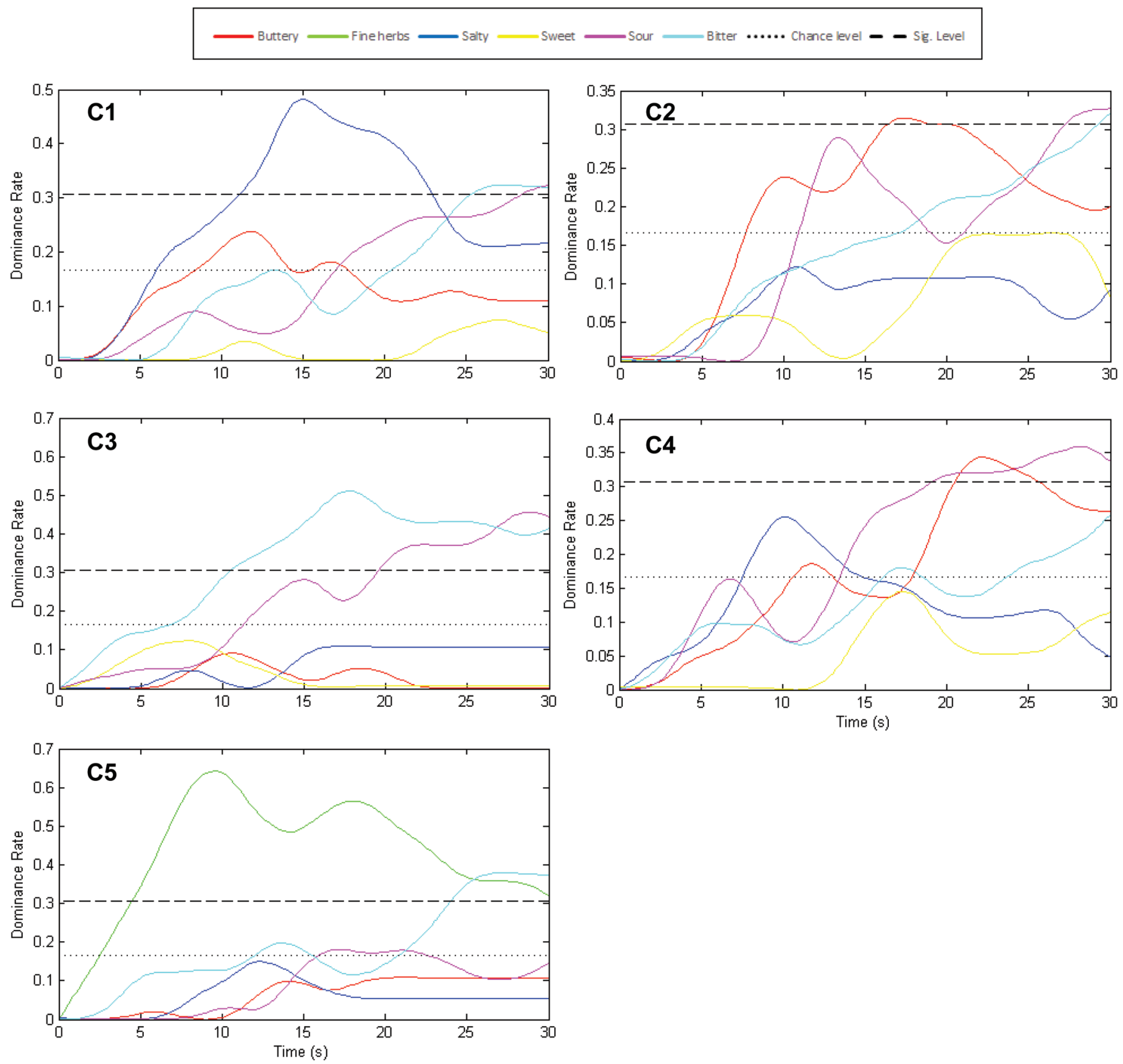

Figure 2. Temporal dominance of sensations curves of dominance rate (i.e., proportion of subjects scoring each attribute) versus standardized time (s) for cheeses. The experimental design comprised 5 different cheese formulations made with $1 \%$ salt as follows: $\mathrm{C} 1$ (NaCl + Lactobacillus casei), C2 (1:1 NaCl:KCl wt/wt + L. casei), C3 (1:1 NaCl:KCl wt/wt $+1 \%$ arginine wt/wt + L. casei $), \mathrm{C} 4(1: 1 \mathrm{NaCl}: \mathrm{KCl} \mathrm{wt} / \mathrm{wt}+1 \%$ yeast extract $\mathrm{wt} / \mathrm{wt}+L$. casei $)$, and $\mathrm{C} 5(1: 1 \mathrm{NaCl}: \mathrm{KCl} \mathrm{wt} / \mathrm{wt}+1 \%$ oregano extract $\mathrm{wt} / \mathrm{wt}+L$. casei $)$. Sig. = significant. Color version available online. 
rated for a higher intensity of fine herbs (13.75), salty (8.87), and bitter (8.86) in QDA, with the dominance of fine herbs and bitter in TDS. In addition, the dominance rate was not related to the attribute intensity in most cases. Similar findings have been reported by Bruzzone et al. (2013) for the texture perception in yogurts.

Considering the dynamic aspect of TDS and the static aspect of QDA, the panelists identified that the salty taste stood out in the control sample $(\mathrm{C} 1$, $100 \% \mathrm{NaCl}$ ) when compared with the sample without addition of flavor enhancers $(\mathrm{C} 2)$, confirming that the salting power of $\mathrm{NaCl}$ is higher than that of $\mathrm{KCl}$. However, QDA was able to identify that 2 of 3 samples containing flavor enhancers (C4 and C5) had similar scores to the control sample $(\mathrm{C} 1)$ for salty taste $(P>$ 0.05 ), suggesting that the flavor enhancers were able to increase saltiness of the reduced-sodium prato cheeses. The behavior of the flavor enhancers was also observed during chewing through TDS; however, for this methodology, none of the samples with addition of flavor enhancers presented dominance curves for the salty taste that exceeded the significant level. Thus, through the dynamic aspect, TDS analysis suggested that the flavor enhancers were not able to increase the salt perception of reduced-sodium prato cheeses. On the other hand, the dominance curves showed that the bitter taste did not reach the significant level only for sample C4 (reduced sodium with addition of yeast extract). This is interesting because it reveals that the flavor enhancer was able to attenuate the bitter taste and allowed the other flavors to be identified as dominant during chewing. Thus, the dynamic analysis of TDS allowed us to identify the positive influence of the flavor enhancer on cheese flavor, masking the off-flavors resulting from sodium reduction, which was not captured by QDA. Therefore, TDS pointed out temporal differences between the samples that did not appear with the conventional sensory profile. According to Ng et al. (2012), an obvious merit of TDS is the discriminating products that shared a similar sensory characteristic.

Although QDA and TDS methodologies were shown to provide both qualitative and quantitative information, they are designed to satisfy different needs. Quantitative descriptive analysis aims to describe and quantify the intensity of a larger number of attributes, whereas TDS illustrates the temporal sequence of dominant sensations. When used together as complementary techniques, they can provide a complete product profile (Ng et al., 2012).

Despite the robust results presented by the static aspect of QDA, the evaluation of an attribute intensity during immediate consumption does not completely reflect the perception relevance of these attributes throughout consumption. However, QDA has the advantage of allowing more attributes to be investigated to acquire a complete sensory profile of the product. On the other hand, TDS provided information on the dynamic of perception after product consumption that was not available using conventional profiling methods. Further studies should be carried out to correlate the results from TDS with those obtained from intensity evaluation performed at different times during consumption.

\section{CONCLUSIONS}

This study demonstrated that QDA and TDS are important tools in the development of products with reduced sodium content. Both methods allowed us to identify and characterize the effect of $\mathrm{KCl}$ and flavor enhancers on the sensory profile of reduced-sodium probiotic prato cheese. The TDS methodology was useful in characterizing the reduced-sodium cheese flavor, providing information about the influence of the formulation variables that was not provided by QDA. Both methods indicated that the flavor enhancers influenced or modified the sensory profile of the reduced-sodium probiotic prato cheese. Quantitative descriptive analysis revealed that the addition of the flavor enhancers yeast and oregano extract increased saltiness of the reducedsodium prato cheeses, and the TDS dominance curves revealed that the addition of yeast extract had a positive influence on cheese flavor because it was capable of minimizing the perception of unpleasant taste (bitterness) resulting from the addition of potassium chloride. Overall, the results demonstrated that the combined use of QDA and TDS was more effective in the sensory evaluation of reduced-sodium probiotic prato cheeses than each cheese on its own.

\section{ACKNOWLEDGMENTS}

The authors acknowledge the Fundação de Amparo á Pesquisa do Estado do Rio de Janeiro (FAPERJ, process number 203975) for financial support in this research.

\section{REFERENCES}

Albenzio, M., A. Santillo, M. Caroprese, D. Ruggieri, F. Napolitano, and A. Sevi. 2013. Physicochemical properties of Scamorza ewe milk cheese manufactured with different probiotic cultures. J. Dairy Sci. 96:2781-2791.

Augusto, M. M. M., M. I. Queiroz, and W. H. Viotto. 2005. Seleção e treinamento de julgadores para avaliação do gosto amargo em queijo prato. Food Sci. Technol. (Campinas) 25:849-852.

Ayyash, M. M., and N. P. Shah. 2011a. Proteolysis of low-moisture Mozzarella cheese as affected by substitution of $\mathrm{NaCl}$ with $\mathrm{KCl}$. J. Dairy Sci. 94:3769-3777. 
Ayyash, M. M., and N. P. Shah. 2011b. The effect of substituting $\mathrm{NaCl}$ with $\mathrm{KCl}$ on Nabulsi cheese: Chemical composition, total viable count, and texture profile. J. Dairy Sci. 94:2741-2751.

Ayyash, M. M., F. Sherkat, P. Francis, R. P. W. Williams, and N. P. Shah. 2011. The effect of sodium chloride substitution with potassium chloride on texture profile and microstructure of Halloumi cheese. J. Dairy Sci. 94:37-42.

Ayyash, M. M., F. Sherkat, and N. P. Shah. 2013. Effect of partial $\mathrm{NaCl}$ substitution with $\mathrm{KCl}$ on the texture profile, microstructure, and sensory properties of low-moisture mozzarella cheese. J. Dairy Res. 80:7-13.

Braghieri, A., A. Girolami, A. Carlucci, N. Piazzolla, A. M. Riviezzi, and F. Napolitano. 2009. Sensory properties affecting acceptability of "bresaola" from Podolian young bulls. J. Sens. Stud. 24:677-697.

Braghieri, A., N. Piazzolla, F. Galgano, N. Condelli, G. De Rosa, and F. Napolitano. 2016. Effect of preservative addition on sensory and dynamic profile of Lucanian dry-sausages as assessed by quantitative descriptive analysis and temporal dominance of sensations. Meat Sci. 122:68-75.

Brandsma, I. 2006. Reducing sodium: A European perspective. Food Technol. 60:24-29.

Bruzzone, F., G. Ares, and A. Giménez. 2013. Temporal aspects of yoghurt texture perception. Int. Dairy J. 29:124-134.

Camo, J., A. Lorés, D. Djenane, J. A. Beltrán, and P. Roncalés. 2011. Display life of beef packaged with an antioxidant active film as a function of the concentration of oregano extract. Meat Sci. 88:174178.

Cruz, A. G., J. A. F. Faria, M. A. R. Pollonio, H. M. A. Bolini, R. M. S. Celeghini, D. Granato, and N. P. Shah. 2011. Cheeses with reduced sodium content: Effects on functionality, public health benefits and sensory properties. Trends Food Sci. Technol. 22:276-291.

Da Silva, T. L. T., V. R. De Souza, A. C. M. Pinheiro, C. A. Nunes, and T. V. M. Freire. 2014. Equivalence salting and temporal dominance of sensations analysis for different sodium chloride substitutes in cream cheese. Int. J. Dairy Technol. 67:31-38.

Desmond, E. 2006. Reducing salt: A challenge for the meat industry. Meat Sci. 74:188-196.

Devezeaux de Lavergne, M., M. van Delft, F. van de Velde, M. A. J. S. van Boekel, and M. Stieger. 2015. Dynamic texture perception and oral processing of semi-solid food gels: Part 1: Comparison between QDA, progressive profiling and TDS. Food Hydrocoll. 43:207-217.

Felicio, T. L., E. A. Esmerino, V. A. S. Vidal, L. P. Cappato, R. K. A Garcia, R. N. Cavalcanti, M. Q. Freitas, C. A. Conte Junior, M. C. Padilha, M. C. Silva, R. S. L. Raices, D. B. Arellano, H. M. A. Bollini, M. A. R. Pollonio, and A. G. Cruz. 2016. Physico-chemical changes during storage and sensory acceptance of low sodium probiotic Minas cheese added with arginine. Food Chem. 196:628-637.

Ferrão, L. L., M. V. S. Ferreira, R. N. Cavalcanti, A. F. A. Carvalho, T. C. Pimentel, H. L. A. Silva, R. Silva, E. A. Esmerino, R. P. C. Neto, M. I. B. Tavares, M. Q. Freitas, J. C. V. Menezes, L. M. Cabral, J. Moraes, M. C. Silva, S. P. Mathias, R. S. L. Raices, G. M. Pastore, and A. G. Cruz. 2018. The xylooligosaccharide addition and sodium reduction in requeijão cremoso processed cheese. Food Res. Int. 107:137-147.

Ferrão, L. L., E. B. Silva, H. L. A. Silva, R. Silva, N. Mollakhalili, D. Granato, M. Q. Freitas, M. C. Silva, R. S. L. Raices, M. C. Padilha, P. B. Zacarchenco, M. I. M. J. Barbosa, A. M. Mortazavian, and A. G. Cruz. 2016. Strategies to develop healthier processed cheeses: Reduction of sodium and fat contents and use of prebiotics. Food Res. Int. 86:93-102.

Galmarini, M. V., M. Visalli, and P. Schlich. 2017. Advances in representation and analysis of mono and multi-intake Temporal Dominance of Sensations data. Food Qual. Prefer. 56:247-255.

Ghawi, S. K., I. Rowland, and L. Methven. 2014. Enhancing consumer liking of low salt tomato soup over repeated exposure by herb and spice seasonings. Appetite 81:20-29.

Janiaski, D. R., T. C. Pimentel, A. G. Cruz, and S. H. Prudencio 2016. Strawberry-flavored yogurts and whey beverages: What is the sensory profile of the ideal product? J. Dairy Sci. 99:5273-5283.
Karimi, R., A. M. Mortazavian, and M. Karami. 2012a. Incorporation of Lactobacillus casei in Iranian ultrafiltered Feta cheese made by partial replacement of $\mathrm{NaCl}$ with KCl. J. Dairy Sci. 95:4209-4222.

Karimi, R., S. Sohrabvandi, and A. M. Mortazavian. 2012b. Sensory characteristics of probiotic cheese. Compr. Rev. Food Sci. Food Saf. 11:437-452.

Labbe, D., P. Schlich, N. Pineau, F. Gilbert, and N. Martin. 2009 Temporal dominance of sensations and sensory profiling: A comparative study. Food Qual. Prefer. 20:216-221.

Liem, D. G., F. Miremadi, and R. S. J. Keast. 2011. Reducing sodium in foods: The effect on flavor. Nutrients 3:694-711.

Macfie, H. J., N. Bratchell, K. Greenhoff, and L. V. Vallis. 1989. Designs to balance the effect of order of presentation and first-order carry-over effects in Hall tests. J. Sens. Stud. 4:129-148.

Mahadevan, K., and L. Farmer. 2006. Key odor impact compounds in three yeast extract pastes. J. Agric. Food Chem. 54:7242-7250.

Ng, M., J. B. Lawlor, S. Chandra, C. Chaya, L. Hewson, and J. Hort. 2012. Using quantitative descriptive analysis and temporal dominance of sensations analysis as complementary methods for profiling commercial blackcurrant squashes. Food Qual. Prefer. $25: 121-134$

Pineau, N., A. G. de Bouillé, M. Lepage, F. Lenfant, P. Schlich, N. Martin, and A. Rytz. 2012. Temporal dominance of sensations: What is a good attribute list? Food Qual. Prefer. 26:159-165.

Pineau, N., P. Schlich, S. Cordelle, C. Mathonnière, S. Issanchou, A Imbert, M. Rogeaux, P. Etiévant, and E. Köster. 2009. Temporal Dominance of Sensations: Construction of the TDS curves and comparison with time-intensity. Food Qual. Prefer. 20:450-455.

Pinheiro, A. C. M. C. A. Nunes, and V. Vietoris. 2013. SensoMaker: A tool for sensorial characterization of food products. Ciên. Agrotecnol. 37:199-201.

Rodrigues, J. F., C. S. Gonçalves, R. C. Pereira, J. D. S. Carneiro, and A. C. M. Pinheiro. 2014. Utilization of temporal dominance of sensations and time intensity methodology for development of low-sodium Mozzarella cheese using a mixture of salts. J. Dairy Sci. 97:4733-4744.

Santiago-López, J, E. Aguilar-Toalá, A. Hernández-Mendoza, B. Vallejo-Cordoba, A. M. Liceaga, and A. F. González-Córdova. 2018. Bioactive compounds produced during cheese ripening and health effects associated with aged cheese consumption. J. Dairy Sci 101:3742-3757.

Silva, H. L. A., C. F. Balthazar, E. A. Esmerino, R. P. C. Neto, R. S Rocha, J. Moraes, R. N. Cavalcanti, R. M. Franco, M. I. B. Tavares, J. S. Santos, D. Granato, R. G. B. Costa, M. Q. Freitas, M. C. Silva, R. S. L. Raices, C. Senaka Ranadheera, F. Nazzaro, A. M. Mortazavian, and A. G. Cruz. 2018a. Partial substitution of $\mathrm{NaCl}$ by $\mathrm{KCl}$ and addition of flavor enhancers on probiotic Prato cheese: A study covering manufacturing, ripening and storage time. Food Chem. 248:192-200.

Silva, H. L. A., C. F. Balthazar, E. A. Esmerino, A. H. Vieira, L. P. Cappato, R. P. C. Neto, S. Verruck, R. N. Cavalcanti, J. B. Portela, M. M. Andrade, J. Moraes, R. M. Franco, M. I. B. Tavares, E. S. Prudencio, M. Q. Freitas, J. S. Nascimento, M. C. Silva, R. S. L. Raices, and A. G. Cruz. 2017. Effect of sodium reduction and flavor enhancer addition on probiotic Prato cheese processing. Food Res. Int. 99:247-255.

Silva, H. L. A., C. F. Balthazar, R. S. Rocha, J. Moraes, E. A. Esmerino, M. C. Silva, R. S. L. Raices, T. C. Pimentel, M. Q. Freitas, and A. G. Cruz. 2018b. Sodium reduction and flavor enhancers addition: Is there an impact on the availability of minerals from probiotic Prato cheese? Lebensm. Wiss. Technol. 93:287-292.

Stone, H., R. Bleibaum, and H. A. Thomas. 2012. Sensory Evaluation Practices. Academic Press, Wageningen, the Netherlands.

Stone, H., and J. L. Sidel. 2004. Sensory Evaluation Practices. 3rd ed. Academic Press, Cambridge, MA. 